Jurnal Sastra Indonesia

\title{
Konflik Batin Tokoh Utama dalam Novel Ada Surga di Rumahku \\ Karya Oka Aurora Sebagai Alternatif Bahan Ajar Pembelajaran Sastra di SMA
}

\author{
Juwariyah ${ }^{\bowtie}$, Sumartini
}

Jurusan Bahasa dan Sastra Indonesia, Fakultas Bahasa dan Seni, Universitas Negeri Semarang, Indonesia

\begin{tabular}{l}
\hline Info Artikel \\
\hline Sejarah Artikel: \\
Diterima November 2018 \\
Disetujui Mei 2019 \\
Dipublikasikan Juli 2019 \\
\hline Kata kunci: \\
Konflik batin, novel, Ada \\
Surga di Rumahmu, bahan \\
ajar.
\end{tabular}

Keywords:

Inner conflict, novel, Ada Surga di Rumahmu, teaching material.

\begin{abstract}
Abstrak
Bahan ajar sastra yang dipilih oleh guru harus menyajikan berbagai nilai yang bisa diaplikasikan siswa dalam kehidupan nyata. Tujuan penelitian ini adalah mendeskripsikan wujud konflik batin yang mengandung nilai-nilai kehidupan novel Ada Surga di Rumahmu karya Oka Aurora. Pendekatan penelitian yang digunakan yaitu deskriptif kualitatif. Sumber data dalam penelitian ini adalah novel berjudul "Ada Surga di Rumahmu” karya Oka Aurora. Metode yang digunakan dalam penelitian ini adalah analisis isi. Data dianalisis menggunakan teori psikopragmatik. Berdasarkan hasil analisis dan pembahasan disimpulkan bahwa wujud konflik batin dalam novel Ada Surga di Rumahmu karya Oka Aurora antara lain pertentangan antara pilihan yang tidak sesuai dengan keinginan, kebimbangan dalam menghadapi permasalahan, serta harapan tidak sesuai dengan kenyataan. Kesesuaian konflik batin yang mengandung nilai-nilai kehidupan dalam novel Ada Surga di Rumahmu karya Oka Aurora dapat dilihat dari aspek psikologi. Rekomendasi dari hasil penelitian diharapkan penyajian bahan ajar pembelajaran sastra di SMA senantiasa diperbaiki, diperbarui dan dimutakhirkan sesuai kebutuhan dan standar yang telah ditentukan.
\end{abstract}

Abstract

Literary teaching materials chosen by the teacher must present various values that can be applied by students in real life. The purpose of this research is to describe the form of inner conflict that contains the values of life in the novel Ada Surga di Rumahmu by Oka Aurora. The research approach used is descriptive qualitative. The data source in this researchis a novel titledAda Surga di Rumahmu by Oka Aurora. The method used in this researchis content analysis. Data was analyzed using psychopragmatic theory. Based on the results of the analysis and discussion, it was concluded that the form of inner conflict in the novel titledAda Surga di Rumahmuby Oka Aurora includes contradictions between choices that are not in accordance with desires, doubts in facing problems, and expectations not in accordance with reality. The values of life contained in the novel titled Ada Surga di Rumahmu by Oka Aurora include moral values, religious values, social values, cultural values and educational values. Compatibility of inner conflict that contain the values of life in the novel Ada Surga di Rumahmu by Oka Aurora can be seen from the aspect of psychology. Recommendations from the results of the study are expected to present literature learning materials in high school always improved, updated and updated according to the needs and standards that have been determined.

\begin{tabular}{lr}
\hline Alamat korespondensi: & P-ISSN 2252-6315 \\
Gedung B1 Lantai 1 FBS Unnes & E-ISSN 2685-9599 \\
Kampus Sekaran, Gunungpati, Semarang, 50229 & \\
E-mail: riyahalhusna7@gmail.com &
\end{tabular}




\section{PENDAHULUAN}

Ki Hajar Dewantara mengartikan pendidikan sebagai daya upaya untuk memajukan budi pekerti, pikiran, serta jasmani anak, agar dapat memajukan kesempurnaan hidup yaitu hidup dan menghidupkan anak yang selaras dengan alam dan masyarakatnya. Pendidikan mampu mengarahkan anak menjadi pribadi yang cerdas dan memiliki budi pekerti. Fungsi pendidikan yaitu menghasilkan manusia yang tangguh dalam kehidupan masyarakat. Melalui pendidikan diharapkan seseorang dapat mengerti dengan akalnya, memahami dengan perasaannya dan dapat menjalankan atau melaksanakan pengetahuan yang sudah didapat dalam kehidupan masyarakat (Suparlan, 2015:58).

Pembelajaran adalah serangkaian kegiatan yang melibatkan informasi dan lingkungan yang disusun secara terencana untuk memudahkan siswa dalam belajar. Maksudnya yaitu pembelajaran dapat mempermudah siswa mempelajari sesuatu melalui berbagai macam media. Peran guru selain sebagai sumber belajar juga sebagai fasilitator dalam belajar-mengajar. Agar kegiatan pembelajaran mencapai hasil yang maksimal perlu diusahakan faktor yang menunjang seperti kondisi pelajar yang baik, fasilitas dan lingkungan yang mendukung, serta proses belajar yang tepat. Dalam pelaksanaan pembelajaran, ketiga faktor yakni siswa, lingkungan, dan instansi sangat berpengaruh terhadap keberhasilan proses belajar.

Pada dasarnya para guru bahasa dan sastra Indonesia mengalami beberapa kendala dalam pembelajaran sastra, salah satunya adalah guru sering merasa kesulitan untuk menentukan bahan ajar yang tepat, sehingga sering menentukan menggunakan bahan ajar tanpa memperhatikan kriteria-kriteria dalam pemilihan bahan ajar. Sementara itu, siswa membutuhkan internalisasi nilai yang relevan dengan kebutuhan dan permasalahn kehidupan mereka saat ini. Hal tersebut dapat diimbangi dengan membaca dan mengapresiasi novel masa kini, tanpa mengabaikan novel masa lama (dahulu). Selain itu, pembelajaran sastra masih menekankan pada sejarah dan teori sastra karena alasan klasik seperti waktu terbatas atau minim, kurikulum yang mengikat, dan demi keberhasilan ujian nasional (Wicaksono, Haryati dan Sumartini 2014: 2).

Pada zaman sekarang, kehadiran novel tidak hanya sebagai media alternatif untuk menyampaikan pesan, namun juga sebagai media representasi seorang tokoh. Sebagian besar novel dilatarbelakangi oleh kisah pengarang atau tokoh untuk memberikan motivasi dan pembelajaran kepada pembaca. Alhasil tidak hanya pesan yang diperoleh oleh pembaca, namun juga motivasi dan pembelajaran dari seorang tokoh yang menginspirasi.

Novel berjudul "Ada Surga di Rumahmu" karya Oka Aurora merupakan salah satu novel yang terinspirasi dari kisah seorang tokoh. Tokoh yang dikisahkan dalam novel tersebut adalah Ustaz Ahmad Al Habsyi. Beliau merupakan salah satu ustaz kondang yang mempunyai kharisma dan perjalanan hidup yang menarik. Novel karya Oka Aurora tersebut bercerita tentang seorang pemuda bernama Ramadan yang berjuang untuk membahagiakan kedua orangtuanya demi mendapatkan ridaNya.

Cerita dalam novel ini memberikan semangat kepada pembaca untuk menghormati kedua orangtua. Selain itu, dalam novel ini juga meyakinkan kepada pembaca bahwa kunci kesuksesan berasal dari rida kedua orangtua. Rasa cinta kepada kedua orangtua yang amat besar mampu mengalahkan ego ramadan yang bertentangan dengan keinginan kedua orangtuanya. Sehingga lahirlah konflik batin peran utama, yakni tokoh bernama ramadan dalam novel tersebut.

Pembelajaran sastra yang semakin memprihatinkan mendorong penulis untuk melakukan penelitian ini dengan memfokuskan pada konflik batin yang dialami tokoh utama dalam novel Ada Surga di Rumahmu karya Oka Aurora. Dari beberapa konflik yang dialami tokoh utama dalam novel Ada Surga di Rumahmu, penulis menemukan beberapa hal yang menyebabkan kejiwaan tokoh utama terguncang, sehingga melakukan segala upaya 
dalam bentuk sikap dan perbuatan sebagai wujud perlindungan diri dari kehidupan yang dibenci. Dari kasus tersebut, pendekatan psikoanalisis difokuskan pada teori Sigmund Freud. Dipilihnya pendekatan dengan fokus teori psikoanalisis Sigmund Freud karena adanya pertimbangan bahwa pendekatan tersebut cocok untuk mengkaji konflik batin yang dialami oleh tokoh utama. Selanjutnya kajian novel Ada Surga di Rumahmu karya Oka Aurora dijadikan pertimbangan sebagai alternatif bahan ajar pembelajaran sastra di SMA.

Penelitian ini sebagaimana umumnya penelitian pendidikan bahasa dan sastra merupakan penelitian kualitatif yang bersifat deskriptif, yaitu dengan menitikberatkan pada segi keilmiahan data, dan kemudian menguraikan secara terperinci fakta-fakta yang ada di dalam data tersebut.

Penelitian ini juga terkait dengan penelitian sebelumnya, yaitu penelitian yang dilakukan Romadhon (2015) dan Turmudzi (2014) yang terkait dengan kajian psikologi sastra. Serta penelitian Hidayati (2014), Jayanti (2015), dan Neina (2015) yang terkait dengan pengembangan model pembelajaran sastra yang bermuatan nilai-nilai pendidikan karakter.

\section{METODE}

Pendekatan yang digunakan dalam penelitian ini adalah pendekatan deskriptif kualitatif. Diana (2016:45) menyatakan pendekatan deskriptif kualitatif menitikberatkan pada segi ilmiah dan mendasarkan pada karakter yang terdapat dalam data, serta menguraikan secara detail fakta-fakta yang terkandung dalam data tersebut.

Dalam penelitian ini, yang dijadikan sumber penelitian, yaitu novel berjudul "Ada Surga di Rumahmu" karya Oka Aurora. Data didapatkan dari menganalisis secara mendalam novel Ada Surga di Rumahmu karya Oka Aurora cetakan pertama, diterbitkan oleh Noura Books (PT Mizan Publika), Anggota IKAPI, Jakarta, Juni 2014 dan terdiri dari 232 halaman. Novel tersebut didistribusikan oleh Mizan Media
Utama (MMU). Secara spesifik, objek penelitian ini meliputi tiga hal yaitu wujud konflik batin dalam novel, nilai-nilai kehidupan yag terkandung dalam novel, serta cara memanfaatkan novel sebagai bahan ajar pembelajaran sastra di SMA.

Teknik pengumpulan data yang digunakan dalam penelitian ini adalah teknik simak dan catat dengan bantuan kartu data. Teknik simak dilakukan dengan cara mengamati kata, kalimat, paragraf maupun kutipan dialog yang mengandung konflik batin dalam novel Ada Surga di Rumahmu. Kemudian data yang telah ditemukan tersebut dikumpulkan dan dicatat dalam kartu data. Selanjutnya menganalisis data menggunakan teori psikopragmatik Sigmund Freud.

Menurut Endraswara

(2008:104)

Psikopragmatik sastra dalam apresiasi berusaha mengungkapkan nilai-nilai pragmatik kehidupan kejiwaan dalam karya tersebut. Jadi, teori psikopragmatik sastra memberikan makna tertentu dalam kehidupan psikis.

Langkah-langkah yang dilakukan dalam menganalisis data meliputi 7 tahap, yakni (1) membaca secara keseluruhan novel "Ada Surga di Rumahmu" karya Oka Aurora secara berulang-ulang, teliti, dan penuh pemahaman serta penghayatan. (2) melakukan teknik pengkodean dengan cara menulis nomor data pada kutipan novel yang mengandung konflik batin. (3) mengidentifikasi kutipan novel yang mengandung konflik batin yang mengandung nilai-nilai kehidupan. Konflik batin yang diidentifikasi khusus pada konflik batin yang dialami oleh tokoh utama. (4) menganalisis kutipan novel Ada Surga di Rumahmu yang mengandung konflik batin yang mengandung nilai-nilai kehidupan. (5) mendeskripsikan hasil analisis konflik batin yang mengandung nilainilai kehidupan. (6) menerapkan hasil analisis konflik batin yang mengandung nilai-nilai kehidupan sebagai bahan ajar. Serta (7) menyimpulkan hasil analisis melalui bentuk tulisan. 


\section{HASIL DAN PEMBAHASAN}

Penelitian Konflik Batin Tokoh Utama dalam Novel Ada Surga di Rumahmu karya Oka Aurora sebagai Alternatif Bahan Ajar Pembelajaran Sastra di SMA ini berupa analisis deskriptif. Hasil penelitian disajikan dalam bentuk tabel kemudian dideskripsikan dalam bentuk pembahasan.

Wujud Konflik Batin yang Mengandung Nilainilai Kehidupan Novel Ada Surga di Rumahmu karya Oka Aurora

Berdasarkan rekapitulasi hasil analisis wujud konflik batin tokoh utama dalam novel Ada Surga di Rumahmu dengan merujuk pada teori psikopragmatik Sigmund Freud dapat diketahui bahwa terdapat wujud konflik batin berupa pertentangan antara pilihan yang tidak sesuai dengan keinginan, wujud konflik batin berupa kebimbangan dalam menghadapi permasalahan, dan wujud konflik batin berupa harapan yang tidak sesuai dengan kenyataan.

Ketiga wujud konflik batin tersebut mengandung nilai-nilaikehidupan seperti nilai moral, nilai agama, nilai sosial, nilai budaya dan nilai pendidikan.

Cara Memanfaatkan Konflik Batin yang Mengandung Nilai-nilai Kehidupan dalam Novel Ada Surga di Rumahmu Karya Oka Aurora Sehingga Dapat Dijadikan sebagai Bahan Ajar Pembelajaran Sastra di SMA

Cara memanfaatkan konflik batin tokoh utama yang mengandung nilai-nilai kehidupan sebagai bahan ajar yaitu dengan dua cara. Cara pertama, yakni pemanfaatan bahan ajar. Kedua, pemanfaatan nilai-nilai kehidupan sebagai bahan soal-soal yang dibutuhkan dalam pembelajaran bahasa Indonesia, khususnya sastra. Pemanfaatan bahan ajar yaitu dengan menggunakan kutipan-kutipan dalam novel $A d a$ Surga di Rumahmu karya Oka Aurora sebagai materi ajar, dan contoh soal-soal yang digunakan sebagai materi ajar bersumber dari novel Surga di Rumahmu karya Oka Aurora.

Cara menggunakan novel Ada Surga di Rumahmu sebagai alternatif bahan ajar pembelajaran sastra di SMA yaitu digunakan dalam penyusunan bahan ajar, dan digunakan sebagai bahan soal-soal yang dibutuhkan pada pelajaran sastra.

\section{Materi atau Bahan Ajar}

Bahan ajar menempati posisi yang sangat penting dari keseluruhan kurikulum, yang harus dipersiapkan agar pelaksanaan pembelajaran dapat mencapai tujuan. Tujuan tersebut harus sesuai dengan standar kompetensi dan kompetensi dasar yang harus dicapai oleh peserta didik. Artinya, bahan ajar yang ditentukan untuk kegiatan pembelajaran hendaknya benar-benar menunjang tercapainya standar kompetensi dan kompetensi dasar, serta tercapainya indikator (Primasari 2016:32). Simpulannya, bahan ajar adalah bahan yang perlu dipersiapkan guru untuk mengajar. Bahan ajar yang digunakan untuk mengajar hendaknya menunjang tercapainya standar kompetensi dan kompetensi dasar yang tercantum dalam kurikulum.

Berikut contoh penyusunan bahan ajar pada pembelajaran sastra pokok bahasan analisis buku fiksi (novel).

KD 3.11 Menganalisis Pesan dari Satu Buku Fiksi yang dibaca

\section{Menganalisis Novel}

Kegiatan menganalisis novel merupakan kegiatan penyelidikan terhadap suatu karya sastra dan bagian dari apresiasi sastra. Adapun unsur-unsur pembangun yang harus diperhatikan dalam menganalisis novel. Unsurunsur tersebut disebut dengan istilah unsur intrinsik. Berikut unsur-unsur intrinsik dalam sebuah novel.

a. Tema

Tema merupakan sebuah makna yang mengikat keseluruhan unsur cerita sehingga cerita itu hadir sebagai sebuah kesatuan yang padu (Nurgiyantoro 2010:80). Tema adalah gagasan utama yang dikembangkan dalam alur cerita. Tema yang sering diangkat oleh pengarang yaitu pendidikan, keluarga, percintaan, persahabatan, kecemburuan, dan sebagainya. 


\section{b. Latar atau Setting}

Latar atau setting yaitu hal yang berhubungan dengan tempat, waktu dan suasana dalam sebuah cerita. Latar berhubungan dengan para tokoh dalam menjalankan perannya.

c. Alur atau Plot

Alur atau plot merupakan jalan dari sebuah cerita. Alur terbagi menjadi tiga macam, yakni alur maju, alur mundur, dan alur campuran.

\section{d. Tokoh dan Penokohan}

Endraswara (2008:179), menjelaskan bahwa tokoh tidak kalah menarik dalam sebuah cerita fiksi. Tokoh adalah figur yang dikenai dan mengenai tindakan psikologis. Melalui tokoh, pembaca dapat memahami alur psikis pengarang.

Menurut Jusriani (2015:4), tokoh adalah pelaku dalam karya sastra. Dalam karya sastra terdapat beberapa tokoh, namun hanya ada satu tokoh yang pasti ada yaitu tokoh utama. Tokoh utama merupakan tokoh yang sangat penting dalam suatu cerita fiksi.

Penokohan adalah cara pengarang menggambarkan dan mengembangkan karakter tokoh dalam sebuah cerita. adapun karakter tokoh meliputi tokoh utama atau sering disebut protagonis, tokoh yang berlawanan dengan tokoh utama atau antagonis, dan tokoh pelerai atau penengah yang sering disebut tritagonis.

e. Sudut Pandang atau Point of view

Sudut pandang atau point of view merupakan cara pengarang memandang atau menempatkan dirinya dalam cerita. Jadi dalam sebuah cerita seakan-akan pengarang dapat menjadi pelaku utama atau orang lain dalam cerita tersebut.

\section{f. Amanat}

Amanat adalah pesan yang ingin disampaikan oleh pengarang keada pembaca suatu cerita. Pesan yang terkandung dalam cerita diharapkan dapat dijadikan contoh dan teladan bagi pembaca.

Berikut kutipan novel Ada Surga di Rumahmu karya Oka Aurorayang digunakan sebagai bahan ajar. (Pada kegiatan inti pembelajaran: mengamati)

\section{Hikayat dari Masjid Al Haram}

(Bagian-3 Novel Ada Surga di Rumahmu karya Oka Aurora)

"Buya," Akhirnya Ramadan memberanikan diri bertanya.

"Apa Buya sudah pernah naik haji?"

"Belum, Nak."

"Kalau Umi?" tanya Raniah dengan suaranya yang halus dan tipis.

"Apalagi Umi," sahut Umi sambil tersenyum.

Raihan ikut-ikutan bertanya. "Tapi, Buya sama Umi mau, ya, naik haji?"

"Yamau pastinya," tukas Raniah cepat. Disergah kakak sulungnya begitu, Raihan buru-buru menunduk. Abuya tersenyum menghibur Raihan, mengusap-usap rambutnya.

"Dimana ada kemauan dan do'a, di situ terbuka jaan," kata Abuya tersenyum. "Kalau sampai sekarang belum juga dibukakan jalan, berarti mungkin kemauannya yang kurang kuat, doanya yang kurang kuat, atau mungkin keduanya."

"Suatu saat nanti, Ramadhan akan bawa Abuya dan Umi naik haji," putus Ramadhan begitu saja.

Umi tersenyum lebar untuk menyembunyikan bibirnya yang mendadak bergetar saat mengamini keinginan tulus anaknya, sambil berharap seluruh malaikat yang turun ke bumi pada Shubuh yang sejuk ini memeluk mimpi Ramadhan dan membawanya ke hadapan Allah.

Aamiin, Anakku....(halaman 18-19)

\section{Soal-soal}

Soal-soal merupakan salah satu alat ukur yang digunakan untuk mengetahui tingkat pemahaman peserta didik pada suatu materi. Soal-soal dapat dikerjakan secara individu maupun kelompok sesuai dengan perintah dan petunjuk yang diberikan oleh guru.

Berikut ini contoh soal-soal yang menggunakan novel Ada Surga di Rumahmu karya Oka Aurora. 
Bacalah novel Ada Surga di Rumahmu karya Oka Aurora dengan cermat dan penuh pemahaman!

(1) Setelah kalian membaca dan mencari berbagai informasi dari berbagai sumber tentang novel Ada Surga di Rumahmu karya Oka Aurora, tentukanlah pengertian novel!

(2) Berikut akan disajikan unsur pembangun dalam novel. Tugas kalian yakni membaca kutipan pada bagian novel Ada Surga di Rumahmu karya Oka Aurora, kemudian identifikasi unsur pembangun yang ada dalam kutipan tersebut!

Kutipan Novel Ada Surga di Rumahmu

Haji Arif kembali sengit. "Apa Ustazz juga memikirkan orang lain? kalau iyo, Ustazz pasti idak akan melakukan perbuatan mudarat itu." "Hati-hati bicaranya, Haji. Jangan memfitnah," sahut Buya Hamid. "Aku idak memfitnah. Memang begitu, bukan, kenyataannyo? Ustazz ini saja yang idak mengaku." "Percuma bicara dengan orang yang hanya memikirkan diri sendiri. Ujung-ujungnya selalu mau menang sendiri," gumam Ramadan sambil berderap menuju pintu keluar. "Cukup, Ramadan!" Abuya menghardiknya. Tapi, Ramadan sudah melangkahi ambang pintu dan menghilang. Ramadan menyadari ujiannya kali ini tidak main-main: fitnah! Meski Ia paham ini tanda Ia akan naik derajat, tak mudah menahan kesabarannya.

\section{Contoh Tabel Unsur Pembangun Novel Ada}

Surga di Rumahmu

\begin{tabular}{|r|l|l|}
\hline $\begin{array}{r}\text { N } \\
\text { o }\end{array}$ & $\begin{array}{l}\text { Novel } \\
\text { Nombangun }\end{array}$ & Keterangan \\
\hline 1. & Tema & \\
\hline 2. & Latar atau Setting & \\
\hline 3. & Alur atau Plot & \\
\hline 4. & Penokohan & \\
\hline 5. & $\begin{array}{l}\text { Sudut pandang atau } \\
\text { point of view }\end{array}$ & \\
\hline 6. & Amanat & \\
\hline
\end{tabular}

(3) Kegiatan selanjutnya, baca kemudian alisislah pesan yang terkandung dalam kutipan novel Ada Surga di Rumahmu karya Oka Aurora dengan cermat!

Contoh Tabel Pesan yang Terkandung dalam

Novel

\begin{tabular}{|l|l|l|l|l|}
\hline No & $\begin{array}{l}\text { Kutip } \\
\text {-an }\end{array}$ & $\begin{array}{l}\text { Wujud } \\
\text { Konflik } \\
\text { Batin }\end{array}$ & $\begin{array}{l}\text { Nilai } \\
\text { Kehidupan }\end{array}$ & $\begin{array}{l}\text { Pesan } \\
\text { yang } \\
\text { Terkan- } \\
\text { dung }\end{array}$ \\
\hline 1. & & & & \\
\hline 2. & & & & \\
\hline 3. & & & & \\
\hline
\end{tabular}

Kesesuaian Konflik Batin yang Mengandung Nilai-nilai Kehidupan dalam Novel Ada Surga di Rumahmu Karya Oka Aurora Sehingga Dapat Dijadikan sebagai Bahar Ajar Pembelajaran Sastra di SMA

Kesesuaian konflik batin yang mengandung nilai-nilai kehidupan dalam novel Ada Surga di Rumahmu karya Oka Aurora sehingga dapat dijadikan sebagai bahan ajar pembelajaran sastra di SMA yang baik dapat dilihat dari aspek psikologi.

Aspek psikologi berkaitan dengan psikologi tokoh, kehidupan tokoh, serta peristiwa yang menyertai tokoh dalam sebuah novel. Beberapa hal tersebut dapat mempengaruhi psikologi peserta didik dalam berpikir dan bersikap serta bertindak. Salah satu tokoh yang dapat mempengaruhi psikologi peserta didik adalah tokoh utama bernama Ramadan.

Ramadan tak tahu alasan mana yang pantas Ia ajukan sebagai keberatan. Sebagai anak laki-laki tertua di keluarga ini, tak pantas rasanya mengeluhkan tinggal berjauhan dengan keluarga. Tak pantas pula mengkhawatirkan hidup mandiri. Lagi pula Ia tahu persis, pesantren milik keluarga ini akan sangat meringankan beban keuangan keluarga. Jika memang masalah utamanya adalah biaya, Ramadan memutuskan untuk ikhlas menuruti saran orangtuanya. Akhirnya dengan suara lirih Ia berkata, "Aku idak keberatan, Buya. Jika 
menurut Umi dan Buya baik untukku, Insya Allah aku siap." (A.12)

Saat Ramadan menerima tawaran dandatang ke Jakarta untuk berdakwah pada salah satustasiun TV, tiba-tiba panitia yang mengundang memberitahukan bahwa mereka salah undang atau salah sasaran. Meski sejumput rasa kecewa sempat meninju hatinya, Ramadan tetap bersabar. Ramadan merupakan orang yang sabar dalam menghadapi berbagai ujian dari Allah.

Secara psikologi, kisah tokoh Ramadan sangat membantu peserta didik SMA untuk menjadikannya contoh. Konflik batin yang mengandung nilai-nilai kehidupan dalam novel ini mampu mengajarkan peserta didik untuk religius, berbakti kepada orang tua dan bercitacita tinggi. Jadi, peserta didik SMA akan lebih terarah dalam bersikap dan bertindak dalam menghadapi masalah yang dihadapi. Berdasarkan uraian di atas, tergambar bahwa psikologi tokoh Ramadan dengan peserta didik SMA sangat terkait. Analisisnya berupa jenjang SMA yang dialami oleh tokoh Ramadan. Hal ini cukup menjadi aspek psikologi yang mendukung konflik batin yang mengandung nilai-nilai kehidupan dalam novel Ada Surga di Rumahmu karya Oka Aurora untuk menjadi bahan ajar pembelajaran sastra di SMA.

\section{SIMPULAN}

Berdasarkan hasil penelitian dan pembahasan pada novel Ada Surga di Rumahmu karya Oka Aurora mengenai wujud konflik batin tokoh utama, nilai-nilai kehidupan dan implementasinya sebagai bahan ajar di SMA, serta kesesuaian konflik batin yang mengandung nilai-nilai kehidupan sehingga dapat dijadikan sebagai bahan ajar pembelajaran sastra di SMA dapat disimpulkan sebagai berikut.

Wujud konflik batin dalam novel $A d a$ Surga di Rumahmu karya Oka Aurora antara lain pertentangan antara pilihan yang tidak sesuai dengan keinginan, kebimbangan dalam menghadapi permasalahan, serta harapan tidak sesuai dengan kenyataan. Ketiga wujud konflik batin tersebut mengandung nilai-nilai kehidupan meliputi nilai moral, nilai agama, nilai sosial, nilai budaya dan nilai pendidikan. Wujud konflik batin dan nilai-nilai kehidupan tersebut dapat mengantarkan peserta didik menjadi pribadi yang berbudi luhur dan berkarakter baik dan dapat dijadikan sebagai bahan ajar pembelajaran sastra di SMA.

Cara memanfaatkan konflik batin tokoh utama yang mengandung nilai-nilai kehidupan sebagai bahan ajar yaitu dengan dua cara. Cara pertama, yakni pemanfaatan bahan ajar. Kedua, pemanfaatan nilai-nilai kehidupan sebagai bahan soal-soal yang dibutuhkan dalam pembelajaran bahasa Indonesia, khususnya sastra. Pemanfaatan bahan ajar yaitu dengan menggunakan kutipan-kutipan dalam novel $A d a$ Surga di Rumahmu karya Oka Aurora sebagai materi ajar, dan contoh soal-soal yang digunakan sebagai materi ajar bersumber dari novel Surga di Rumahmu karya Oka Aurora.

Kesesuaian konflik batin yang mengandung nilai-nilai kehidupan dalam novel Ada Surga di Rumahmu karya Oka Aurora dapat dilihat dari aspek psikologi. Berdasarkan aspek psikologi, konflik batin yang terkandung dalam novel ini sangat tepat diajarkan kepada peserta didik jenjang SMA karena pengarang juga menceritakan tokoh utama semasa SMA.

Berbagai perbaikan dan revisi dapat dilakukan oleh peneliti selanjutnya dalam menganalisis konflik batin dalam novel $A d a$ Surga di Rumahmu karya Oka Aurora dengan cara melakukan penelitian secara lebih mendalam dan inovatif. Di samping itu, guru bahasa Indonesia hendaknya mempertimbangkan bahan ajar yang akan digunakan dalam pembelajaran sastra di SMA agar siswa mendapatkan materi yang sesuai dengan kebutuhan serta sebagai bekal dalam mengembangkan diri menjadi pribadi yang berkarakter.

\section{DAFTAR PUSTAKA}

Aurora, Oka. (2014). Ada Surga di Rumahmu. Jakarta: Noura Books.

Diana, Ani. (2016). "Analisis Konflik Batin Tokoh Utama dalam Novel Wanita di Lautan Sunyi Karya Nurul Asmayani."Jurnal Pesona. 
Program Studi Pendidikan Bahasa dan Sastra Indonesia, STKIP Muhammadiyah Pringsewu Lampung.

Endraswara, Suwardi. (2008). Metode Penelitian Psikologi Sastra. Yogyakarta: Media Pressindo.

Hidayati, Erni. (2014). "Pengembangan Model Lingkar Sastra dalam Pembelajaran Apresiasi Cerita Pendek Bermuatan Nilai-niai Pendidikan Karakter Peserta Didik SMP/MTs."Jurnal Seloka Pendidikan Bahasa dan Sastra Indonesia Universitas Negeri Semarang.

Jayanti, dkk. (2015). "Pengembangan Buku Pengayaan Menulis Cerita Biografi Bermuatan Nilai-nilai Pendidikan Karakter Bagi Pesrta Didik Kelas VIII SMP."Jurnal Seloka Pendidikan Bahasa dan Sastra Indonesia Universitas Negeri Semarang.

Jusriani. (2015). "Konflik Tokoh dalam Novel Rindu Karya Tere Liye: Tinjauan Psikologi Sastra." Jurnal Humanika. Universitas Halu Oleo.

Neina, dkk. (2015). "Pengembangan Buku Pengayaan Menulis Cerita Anak Bermuatan Nilai Karakter Berdasarkan Content and Languange Learning (CLIL) untuk Siswa Sekolah Dasar Kelas Tinggi." Jurnal Seloka Pendidikan Bahasa dan Sastra Indonesia Universitas Negeri Semarang.

Nurgiyantoro, Burhan. (2010). Sastra Anak. Yogyakarta: Gadjah Mada University Press.

Primasari, Desilia. (2016). "Analisis Sosiologi Sastra dan Nilai Pendidikan Karakter Novel Pulang Karya Leila S. Chudori serta Relevansinya sebagai Materi Ajar Apresiasi Sastra di Sekolah Menengah Atas."Skripsi. Program Studi Pendidikan Bahasa Indonesia, Universitas Sebelas Maret.

Romadhon. (2015). "Perilaku Tokoh Utama Novel Saksi Mata Karya Suparto Brata: Kajian Psikologi Sastra." Jurnal Sastra Indonesia Universitas Negeri Semarang.

Suparlan, Henricus. (2015). "Filsafat Pendidikan Ki Hadjar Dewantara dan Sumbangannya bagi Pendidikan Indonesia." Jurnal Filsafat. Program Studi Psikologi, Universitas Sarjanawiyata Tamansiswa.

Turmudzi, dkk. (2014). "Watak dan Perilaku Tokoh Jumena Martawan Tanpa Dasar Karya Arifin C. Noer." Jurnal Sastra Indonesia Universitas Negeri Semarang.

Wicaksono, dkk. (2014). "Novel Negeri 5 Menara Karya Ahmad Fuadi sebagai Pilihan Bahan Ajar Sastra Indonesia di SMA." Jurnal Sastra Indonesia. Program Studi Bahasa dan Sastra Indonesia, Universitas Negeri Semarang. 